\title{
Backstepping sliding mode control of a variable speed wind turbine for power optimization
}

\author{
Saravanakumar RAJENDRAN, Debashisha JENA ( $ه)$
}

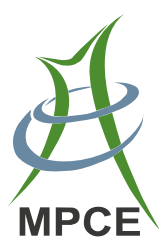

\begin{abstract}
To optimize the energy capture from the wind, wind turbine (WT) should operate at variable speed. Based on the wind speed, the operating regions of the WT are divided into two parts: below and above the rated wind speed. The main aim at below rated wind speed is to maximize the energy capture from the wind with reduced oscillation on the drive train. At above rated wind speed, the aim is to maintain the rated power by using pitch control. This paper presents the control of WT at below rated wind speed by using backstepping sliding mode control (BSMC). In BSMC, generator torque is considered as the control input that depends on the optimal rotor speed. Usually, this optimal rotor speed is derived from effective wind speed. In this paper, effective wind speed is estimated from aerodynamic torque and rotor speed by using the modified Newton Rapshon (MNR) algorithm. Initially, a conventional sliding mode controller (SMC) is applied to the WT, but the performance of the controller was found to be less robust with respect to disturbances. Generally, WT external disturbance is not predictable. To overcome the above drawback, BSMC is proposed and both the controllers are tested with mathematical model and finally validated with the fatigue, aerodynamics, structures, and turbulence (FAST) WT simulator in the presence of disturbances. From the results, it is concluded that the proposed BSMC is more robust than conventional SMC in the presence of disturbances.
\end{abstract}

CrossCheck date: 3 December 2014

Received: 30 August 2014/ Accepted: 6 February 2015/Published online: 10 March 2015

(C) The Author(s) 2015. This article is published with open access at Springerlink.com

S. RAJENDRAN, D. JENA, National Institute of Technology

Karnataka, Surathkal, India

(凹) e-mail: bapu4002@gmail.com
Keywords Nonlinear control, Single mass model, Modified Newton Raphson (MNR), Backstepping sliding mode control (BSMC)

\section{Introduction}

Due to the environment and global climate change, renewable energy sources play a vital role in energy market. Out of several renewable energy sources, wind energy is one of the most reliable and environment friendly energy source. In general, kinetic energy of the wind is converted to the electrical energy by using WT. In literature, many wind power technologies are available to improve the significant power growth in wind energy sector. Generally, there are two major classifications of WT, i.e. variable and fixed speed WT. By comparing this two classifications, variable speed WT (VSWT) is more versatile than fixed speed. The main advantages of VSWT are high power quality, reduced mechanical stress and increased power output by $10 \% \sim 15 \%$ annually $[1,2]$. WT operating region is broadly classified into. below and above rated wind speed. At below rated wind speed, a torque control is used to maximize the energy capture and at above rated wind speed, pitch control is used to maintain the rated power. In literature, several papers reported for extracting maximum power at below rated wind speed. In [3], adaptive neuro fuzzy inference system (ANFIS) is used to maintain the maximal output power of the turbine. In order to improve the power at erratic wind speed regime wind generator equipped with continuous variable transmission (CVT) was proposed. ANFIS is used to adjust the system speed in order to regulate at highest efficiency. Extraction of maximum power by using neural network $(\mathrm{NN})$ based pitch controller of a grid connected wind turbine is discussed in [4]. In [5], a back stepping control is used to control VSWT 
with permanent magnet synchronous generator. The proposed algorithm is used to eliminate the parameter uncertainty both in electrical and mechanical systems, and it ensures the minimum generator velocity tracking error. Some of the literature reported the maximum power extraction without using the wind speed information. In [6], the combination of linear control for blade pitch angle and nonlinear $\mathrm{H}_{\infty}$ torque control with super twisting observer is discussed. Without using the wind velocity, $\mathrm{H}_{\infty}$ torque control is able to accommodate the dynamics of the wind and WT with the mitigation of input and output disturbances of the systems.

Fuzzy logic controller (FLC) is developed for maximum power extraction at below rated wind speed [7]. The main aim of the FLC is to track the optimal power by adjusting the rotational speed of the turbine. The advantage of FLC is that, it doesn't require any information about the wind speed. Input to the FLC is rotor speed and mechanical power output, and output is reference rotor speed. Radial bias function based NN control for variable speed variable pitch WT is proposed in [8] for various operating regions of wind speed. NN control can able to approximate the nonlinear dynamics of WT input and output measurements and it can ensure the smooth tracking of optimal tip speed ratio at different wind speeds. Lyapunov stability approach is used for updating the NN weights. Nonlinear static and dynamic state feedback linearization control for power optimization is addressed in [9, 10], where both the single and two mass model are taken into consideration and the wind speed is estimated by Newton Rapshon (NR) method. To extract the optimal power at below rated wind speed, using adaptive fuzzy integral sliding mode control (AFISMC) with the different types of input disturbance (maximum $10 \mathrm{kNm}$ ) for variable speed wind turbine is presented in [11]. The proposed controller is tested with different mean wind speed in order to ensure the robustness of the controller. In [12], fuzzy sliding mode controller (FSMC) based maximum power extraction for VSWT is proposed. In [13], electromagnetic interaction with doublyfed induction machine (DFIG) is used for wind farm power smoothing. The adaptability of the proposed controller is tested with model uncertainty of the WT system with the presence of disturbance of $1 \mathrm{kNm}$. From the analysis, it is concluded that a tradeoff is maintained between maximum power capture and drive train oscillation. The wind speed is estimated by using modified Newton Rapshon (MNR) for above two references. In this work, backstepping sliding mode control (BSMC) based control of WT for maximum power capture is proposed. The proposed BSMC is initially tested with mathematical model and finally validated through fatigue, aerodynamics, structures, and turbulence (FAST) model. It is also clear that compared to sliding mode controller(SMC), BSMC is robust with respect to disturbances. One more advantage compared to [12-14] is that no additional soft computing technique is required to extract the maximum power; BSMC itself is able to accommodate the disturbance level up to 10 $\mathrm{kNm}$.

The motivation of the proposed control strategy is that, without any addition of soft computing techniques or complex control law, the proposed control technique can able to achieve the control objective, i.e. maximum power capture and reduced transient on the drive train with different level of disturbances. Some of the controllers are not robust with respect to disturbances so that they may go for adaptive controller, but the proposed controller in this work is enough to accommodate the additive disturbance of 10 $\mathrm{kNm}$. The controller is validated using FAST wind turbine model with different mean wind speed. This paper is organized as follows. Section 2 describes the WT model dynamics for single mass model. Section 3 describes the control objectives for below rated wind speed and explains about SMC and BSMC control algorithms. The com- parisons for conventional SMC and proposed BSMC controllers for mathematical and FAST model are discussed in section 4. Finally, a conclusion is drawn in section 5.

\section{WT model}

WT is a device which converts the kinetic energy of the wind into electric energy. Simulation complexity of the WT purely depends on the type of control objectives. In case of WT modelling, complex simulators are required to verify the dynamic response of multiple components and aerodynamic loading. Generally, dynamic loads and interaction of large components are verified by the aero elastic simulator. For designing a WT controller, instead of going with complex simulator, the design objective can be achieved by using simplified mathematical model. In this work, WT model is described by the set of nonlinear ordinary differential equation with limited degree of freedom. Initially, this paper describes the control law for a simplified mathematical model with the objective of optimal power capture at below rated wind speed. Finally, the same control law is applied for FAST simulator. Generally, VSWT system consists of the following components, i.e. aerodynamics, drive trains, and generator.

Equation (1) gives the nonlinear expression for aerodynamic power capture by the rotor.

$P_{a}=\frac{1}{2} \rho \pi R^{2} C_{P}(\lambda, \beta) v^{3}$

where $\rho$ is the air density; $R$ is the rotor diameter; $v$ is the wind speed; and $\omega_{r}$ is the rotor speed. It is clear that the aerodynamic power $P_{a}$ is directly proportional to the cube 
of the wind speed. The power coefficient $C_{P}$ is the function of blade pitch angle $\beta$ and tip speed ratio $\lambda$. The tip speed ratio is defined as ratio between linear tip speed and wind speed.

$\lambda=\frac{\omega_{r} R}{v}$

Generally, wind speed is stochastic, which leads to variation in power coefficient. The relationship between aerodynamic torque $T_{a}$ and the aerodynamic power is given in (3).

$P_{a}=T_{a} \omega_{r}$

$T_{a}=\frac{1}{2} \rho \pi R^{3} C_{q}(\lambda, \beta) v^{2}$

where $C_{q}$ is the torque coefficient given as

$C_{q}(\lambda, \beta)=\frac{C_{P}(\lambda, \beta)}{\lambda}$

Substituting (5) in (4), we get

$T_{a}=\frac{1}{2} \rho \pi R^{3} \frac{C_{P}(\lambda, \beta)}{\lambda} v^{2}$

The nonlinear term above is $C_{p}$, which can be approximated by the $5^{\text {th }}$ order polynomial given in (7).

$$
\begin{aligned}
C_{P}(\lambda) & =\sum_{n=0}^{5} a_{n} \lambda^{n} \\
& =a_{0}+\lambda a_{1}+\lambda^{2} a_{2}+\lambda^{3} a_{3}+\lambda^{4} a_{4}+\lambda^{5} a_{5}
\end{aligned}
$$

where $a_{0}$ to $a_{5}$ are the WT power coefficients. The values of approximated coefficients are: $a_{0}=0.1667 ; a_{1}=$ $-0.2558 ; \quad a_{2}=0.115 ; \quad a_{3}=-0.01617 ; \quad a_{4}=0.00095 ;$ $a_{5}=-2.05 \times 10^{-5}$.

Fig. 1 shows the two mass model of the WT. Equation (8) represents dynamics of the rotor speed $\omega_{r}$ with rotor inertia $J_{r}$ driven by the aerodynamic torque $T_{a}$.

$J_{r} \dot{\omega}_{r}=T_{a}-T_{l s}-K_{r} \omega_{r}$

Braking torque acting on the rotor is low speed shaft torque $T_{l s}$ which can be derived by using stiffness and damping factor of the low speed shaft given in (9).

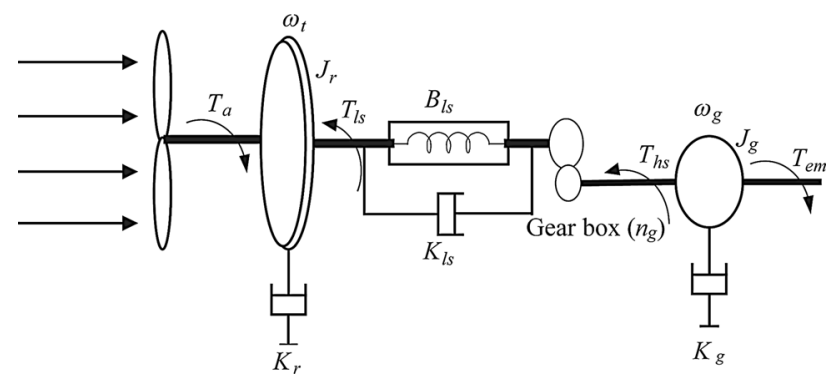

Fig. 1 Two mass model of the aero turbine
$T_{l s}=B_{l s}\left(\theta_{r}-\theta_{l s}\right)+K_{l s}\left(\omega_{r}-\omega_{l s}\right)$

Equation (10) represents dynamics of the generator speed $\omega_{g}$ with generator inertia $J_{g}$ driven by the high speed shaft torque $T_{h s}$ and braking electromagnetic torque $T_{e m}$.

$J_{g} \dot{\omega}_{g}=T_{h s}-K_{g} \omega_{g}-T_{e m}$

Gearbox ratio is defined as

$n_{g}=\frac{T_{l s}}{T_{h s}}=\frac{\omega_{g}}{\omega_{l s}}$

If a perfectly rigid low-speed shaft is assumed, the dynamics of the rotor characteristics of a single mass WT model can be expressed by a first order differential equation given in (12) to (14).

$J_{t} \dot{\omega}_{r}=T_{a}-T_{g}-K_{t} \omega_{r}$

$J_{t}=J_{r}+n_{g}^{2} J_{g}$

$K_{t}=K_{r}+n_{g}^{2} K_{g}$

\section{Control objective}

Generally, variable speed WT has two region of control, below rated speed and above rated speed. At below rated speed, the objectives are to maximize the energy capture from the wind and reduce the drive train oscillations. To limit the power capture at above rated speed, a pitch controller is used. In this paper, conventional SMC and proposed BSMC controllers are used to extract the optimal power at below rated speed.

The objective of the controllers is to track the optimal rotor speed $\omega_{\text {ropt }}$ that ensures the optimal power capture provided the stress on the low speed shaft torque is minimum. For high wind speed (above rated speed), the pitch angle is an additional control input to the WT. Fig. 2 shows the WT control schemes. From the figure, it is clear that WT has two control loop: inner and outer loop. The inner control loop consists of electrical generator with power converters. The outer loop having the aero turbine control which gives the reference to the inner loop is shown in Fig. 2. In this paper, we made an assumption that, the inner loop is well controlled. In most of the time, the wind speed

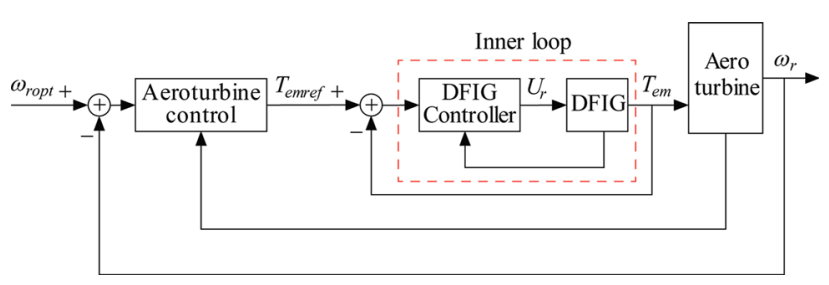

Fig. 2 WT control scheme 
operated at below rated speed. The two main objectives in this region are presented as the following.

1) Maximizing the aerodynamic power.

2) Reducing the low speed shaft torque transient.

The $C_{P}(\lambda, \beta)$ has the unique maximum corresponding to the optimal value of $\lambda_{\text {opt }}$ and $\beta_{\text {opt }}$ given in (15).

$C_{P}\left(\lambda_{\text {opt }}, \beta_{\text {opt }}\right)=C_{P_{\text {opt }}}$

where $\lambda_{\text {opt }}$ is defined as

$\lambda_{\text {opt }}=\frac{\omega_{\text {ropt }} R}{v}$

At below rated region, to maximize the power capture, the blade pitch angle $\beta$ is fixed to the optimal value $\beta_{\text {opt }}$ and tip speed ratio is fixed to its optimal value $\lambda_{\text {opt }}$. The optimal/reference rotor speed is defined in (17).

$\omega_{\text {ropt }}=\frac{\lambda_{\text {opt }} v}{R}$

\subsection{Wind speed estimation}

The estimation of effective wind speed is related to aerodynamic torque and rotor speed provided the pitch angle is at optimal value.

$T_{a}=\frac{1}{2} \rho \pi R^{3} \frac{C_{P}(\lambda)}{\lambda} v^{2}$

The aero dynamic power coefficient is approximated by a $5^{\text {th }}$ order polynomial as given in (7).

$F(v)=T_{a}-\frac{1}{2} \rho \pi R^{3} \frac{C_{P}(\lambda)}{\lambda} v^{2}$

The estimated wind speed can be obtained by solving (19) using MNR. The above equation has unique solution at below rated region. With known ' $v$ ', the optimal rotor speed $\omega_{\text {ropt }}$ is calculated by using (17).

\subsection{Sliding mode control (SMC)}

To achieve the maximum power at below rated wind speed, sliding mode based torque control is proposed in [14]. The main objective of this controller is to track the reference rotor speed $\omega_{\text {ref }}$ for maximum power extraction.

The WT single mass model can be rearranged as given in (20).

$\dot{\omega}_{r}=\frac{1}{J_{t}} T_{a}-\frac{K_{t}}{J_{t}} \omega_{r}-\frac{1}{J_{t}} T_{g}$

For speed control, a sliding surface is defined as

$S(t)=\omega_{r}(t)-\omega_{\text {ref }}(t)$

The reference rotor speed is given by (17).

Taking the time derivative of (21), we get
$\dot{S}(t)=\dot{\omega}_{r}(t)-\dot{\omega}_{r e f}(t)$

By substituting $\dot{\omega}_{r}$ in the above equation, we get

$\dot{S}=\frac{1}{J_{t}} T_{a}-\frac{K_{t}}{J_{t}} \omega_{r}-\frac{1}{J_{t}} T_{g}-\dot{\omega}_{r e f}$

The stability of the SMC cab be evaluated by using Lyapunov candidate function.

$V=\frac{1}{2} S^{2}$

Taking the time derivative of (24):

$\dot{V}=S \dot{S}=S\left[\frac{1}{J_{t}} T_{a}-\frac{K_{t}}{J_{t}} \omega_{r}-\frac{1}{J_{t}} T_{g}-\dot{\omega}_{r e f}\right]$

To make $\dot{V}$ negative definite, the following control law is designed as

$\frac{1}{J_{t}} T_{a}-\frac{K_{t}}{J_{t}} \omega_{r}-\frac{1}{J_{t}} T_{g}-\dot{\omega}_{\text {ref }}\left\{\begin{array}{c}<0 \text { for } S>0 \\ >0 \text { for } S<0\end{array}\right\}$

Stability of the controller is achieved provided the torque control satisfies (27).

$T_{g}\left\{\begin{array}{c}<T_{a}-K_{t} \omega_{r}-J_{t} \dot{\omega}_{r e f} \text { for } S>0 \\ >T_{a}-K_{t} \omega_{r}-J_{t} \dot{\omega}_{\text {ref }} \text { for } S<0\end{array}\right\}$

Generally, the SMC have two parts, equivalent control $U_{e q}$ and switching control $U_{s w}$. By combining these two controls, the stability of the controller can be satisfied with minimum tracking error.

$U(t)=U_{e q}+U_{s w}$

The switching control is defined in two ways:

$U_{s w}=k \operatorname{sign} \frac{S}{\varphi}$

or

$U_{s w}=k \tanh \frac{S}{\varphi}$

Finally, the torque control structure is given in (31).

$T_{g}=T_{a}-K_{t} \omega_{r}-J_{t} \dot{\omega}_{r e f}+J_{t} k \tanh \frac{S}{\varphi}$

where $k$ is the sliding gain, tanh is the hyperbolic tangent function and sign is signum function.

\subsection{Backstepping sliding mode controller (BSMC) $[15,16]$}

WT is an autonomous nonlinear system and its mathematical model is expressed as 
$\dot{x}_{1}=x_{2}$

$\dot{x}_{2}=\frac{1}{J_{t}} T_{a}-\frac{K_{t}}{J_{t}} \omega_{r}-\frac{1}{J_{t}} T_{g}+d$

$y=x_{2}$

where $x_{1}$ is the position of the rotor; $x_{2}$ is the rotor speed; and $d$ is the disturbance (maximum value of disturbance $d$ is $10 \mathrm{kNm}$ ). The main objective of BSMC is to perform in such a way that the tracking error can be minimized in the presence of various levels of disturbances.

$e_{1}=\theta_{r}-\theta_{\text {ref }}$

then

$\dot{e}_{1}=\dot{\theta}_{r}-\dot{\theta}_{r e f}$

$\dot{e}_{1}=z_{1}-\dot{\theta}_{r e f}$

The stabilizing function is defined as

$\alpha_{1}=c_{1} e_{1}$

where $\alpha_{1}$ is the stable coefficient and $c_{1}$ is the positive constant.

The speed tracking error of the WT is defined as

$e_{2}=\dot{e}_{1}+\alpha_{1}$

The first Lyapunov function is given as

$V_{1}=0.5 e_{1}^{2}$

By taking the derivative of the above function, we get

$\dot{V}_{1}=e_{1} \dot{e}_{1}$

$e_{2}=z_{1}-\dot{\theta}_{r e f}+\alpha_{1}$

$\dot{V}_{1}=e_{1}\left(z_{1}-\dot{\theta}_{r e f}\right)$

$\dot{V}_{1}=e_{1}\left(e_{2}-\alpha_{1}\right)=e_{1} e_{2}-c_{1} e_{1}^{2}$

Taking the derivative of $e_{2}$, we get

$\dot{e}_{2}=\dot{z}_{1}-\ddot{\theta}_{r e f}+\dot{\alpha}_{1}$

By substituting $\dot{\omega}_{r}$ in (45), we get

$\dot{e}_{2}=\frac{T_{a}}{J_{t}}-\frac{T_{g}}{J_{t}}-\frac{K_{t}}{J_{t}} \omega_{r}-\ddot{\theta}_{r e f}+\dot{\alpha}_{1}$

The second Lyapunov function is defined as

$V=V_{1}+0.5 \sigma^{2}$

where $\sigma$ is the sliding surface.

$\sigma=e_{1}+e_{2}$

By taking the derivative of the second Lyapunov function:

$$
\begin{aligned}
\dot{V} & =\dot{V}_{1}+\sigma \dot{\sigma} \\
& =e_{1} e_{2}-c_{1} e_{1}^{2}+\sigma \dot{\sigma} \\
& =e_{1} e_{2}-c_{1} e_{1}^{2}+\sigma\left(\dot{e}_{1}+\dot{e}_{2}\right)
\end{aligned}
$$

By substituting $\dot{e}_{1}$ and $\dot{e}_{2}$ from (36) and (46) in (49), we will get

$$
\begin{aligned}
\dot{V}= & e_{1} e_{2}-c_{1} e_{1}^{2} \\
& +\sigma\left(\left(e_{2}-c_{1} e_{1}\right)+\frac{T_{a}}{J_{t}}-\frac{T_{g}}{J_{t}}-\frac{K_{t}}{J_{t}} \omega_{r}-\ddot{\theta}_{r e f}+\dot{\alpha}_{1}\right)
\end{aligned}
$$

Finally, back stepping sliding mode control law $T_{g}$ is defined as

$$
\begin{aligned}
T_{g}= & T_{a}-K_{t} \omega_{r}-J_{t}\left(\ddot{\theta}_{r e f}-\dot{\alpha}_{1}-\left(e_{2}-c_{1} e_{1}\right)\right) \\
& +J_{t}\left(e_{2}+k \tanh (\sigma)\right)
\end{aligned}
$$

where $k$ is the sliding gain.

By substituting $T_{g}$ in (50), we will get

$\dot{V} \leq-c_{1} e_{1}^{2}-e_{2}^{2}-k \sigma \tanh (\sigma)$

In above equation, the third term $\sigma \tanh (\sigma)$ is always positive, so that the entire equation becomes negative provided $\sigma$ satisfies the following conditions.

if $\sigma$ is + ve and $\tanh (\sigma)+$ ve then $\sigma \tanh (\sigma)+$ ve

if $\sigma$ is - ve and $\tanh (\sigma)-$ ve then $\sigma \tanh (\sigma)+$ ve

Equation (52) can be written as

$\dot{V}=-\boldsymbol{e}^{\mathrm{T}} \boldsymbol{Q} \boldsymbol{e}-k s \tanh (s)$

where $\mathrm{T}$ is transpose and $\boldsymbol{Q}$ is a positive definite symmetric matrix with the form:

$\boldsymbol{Q}=\left[\begin{array}{ll}a & b \\ b & c\end{array}\right]=\left[\begin{array}{cc}c_{1} & 0 \\ 0 & 1\end{array}\right]$

The following condition is used to verify the $\boldsymbol{Q}$ to be positive definite.

Condition 1: $a, c \geq 0$

Condition 2: $a c-b^{2} \geq 0$

In this problem, by verifying the above condition, $c_{1}$ should always positive then the $\boldsymbol{Q}$ matrix is positive definite, $\boldsymbol{e}=\left[\begin{array}{ll}e_{1} & e_{2}\end{array}\right]^{\mathrm{T}}$. In general, $\dot{V}\langle 0$ (negative definite) is referred as the asymptotic stability. But in the case $\dot{V} \leq 0$ (negative semi definite), Lasalles's invariance principle is not possible to prove the stability. In order to avoid this problem, Barbalat's Lemma [17] is used.

Theorem 1 To verify the above theorem, the Lyapunov like lemma is used.

If $\dot{V}(x, t)$ is a scalar function, the following conditions are satisfies. 
1) $\dot{V}(x, t)$ is lower bounded.

2) $\dot{V} \leq 0$ negative semi definite.

3) $\dot{V}$ is uniformly continuous provided $\ddot{V}$ exists and bounded.

Then

$$
\dot{V} \rightarrow 0 \text { as } t \rightarrow \infty
$$

If the function $g(t)$ is differentiable and have the limit, i.e. $g \rightarrow L$ and $\dot{g}$ is uniformly continuous, then $\dot{g} \rightarrow 0$. The necessary condition for $\dot{g} \rightarrow 0$ as $t \rightarrow \infty$ is $\ddot{g}$ should exists and bounded.

$H(t)=\boldsymbol{e}^{\mathrm{T}} Q \boldsymbol{e}+k|\sigma| \leq-\dot{V}_{2}\left(e_{1}(t), e_{2}(t)\right)$

Then

$\lim _{t \rightarrow \infty} \int_{0}^{t} H(\tau) d \tau \leq V\left(e_{1}(0), e_{2}(0)\right)-V\left(e_{1}(t), e_{2}(t)\right)$

Since $V\left(e_{1}(0), e_{2}(0)\right)$ is bounded and $V\left(e_{1}(t), e_{2}(t)\right)$ is non increasing and bounded, the following result can be concluded. Moreover, $\dot{H}(t)$ is also bounded. It indicates $H(t)$ is continuous. In order to make $H(t)$ continuous, the Barbalat's lemma is used.

$\lim _{t \rightarrow \infty} \int_{0}^{t} H(\tau) d \tau<\infty$

The above equation ensures the system stability. Then $e_{1}$ and $e_{2}$ converges to zero as $t \rightarrow \infty$. From this analysis, it is concluded the backstepping controller is asymptotically stable in the presence of parameter uncertainty and external disturbances.

\section{Result and discussion}

The numerical simulations are performed for mathematical model and controls advanced research turbine (CART3) WT model. The WT characteristics of CART3 model are given in Table 1. The main components of the CART3 are rotor, tower and nacelle. The main advantage of the FAST code is that it can able to model the multi body formulation of the WT dynamics. In general, CART3 allows up to 24 degree of freedom (DOF), and it is possible

Table 1 Wind turbine characteristics

\begin{tabular}{ll}
\hline Rotor diameter & $43.3 \mathrm{~m}$ \\
Gear ratio & 43.165 \\
Hub height & $36.6 \mathrm{~m}$ \\
Generator system electrical power & $600 \mathrm{~kW}$ \\
Maximum rotor torque & $162 \mathrm{kNm}$ \\
Maximum rotor speed & $6.73 \mathrm{rad} / \mathrm{sec}$ \\
\hline
\end{tabular}

to turn on or off any DOF [18]. The CART3 variable speed variable pitch WT having the power rating of $600 \mathrm{~kW}$ and it is located in National Renewable Energy Laboratory (NREL) National Wind centre near Golden, Colora. The proposed adaptive control is implemented on the model using a Simulink interface provided in FAST.

\subsection{Mathematical model with proposed and conventional controller}

The test wind profile with full field turbulence is generated by using TurbSim developed by NREL. Figure. 3 shows the hub height wind speed profile. In general, wind speed consists of two components, mean wind speed and turbulence component. The test wind speed consists of 10 min dataset that was generated using Class A Kaimal turbulence spectra. It has the mean value of $7 \mathrm{~m} / \mathrm{s}$ at the hub height, turbulence intensity of $25 \%$ and normal International Electro technical Commission (IEC) turbulence type. The above wind speed is used as the excitation of WT.

Figure 4 shows the rotor speed comparison for SMC and BSMC controller. It is clear that SMC is not able to track the reference rotor speed because of the disturbance of 3 $\mathrm{kNm}$. Due to this, SMC introduces the power loss in the WT system. It can be easily seen that BSMC can able to accommodate the disturbance level of up to $10 \mathrm{kNm}$ with minimum tracking error in the reference rotor speed. Therefore, BSMC is more robust with respect to disturbances. Fig. 5 shows the comparison for generator torque for SMC and BSMC. This figure is further analyzed with Table 2.

$$
\eta_{\text {aero }}(\%)=\frac{\int_{t_{\text {ini }}}^{t_{\text {fin }}} P_{a} \mathrm{~d} t}{\int_{t_{\text {tini }}}^{t_{\text {in }}} P_{a_{\text {opt }}} \mathrm{d} t}
$$

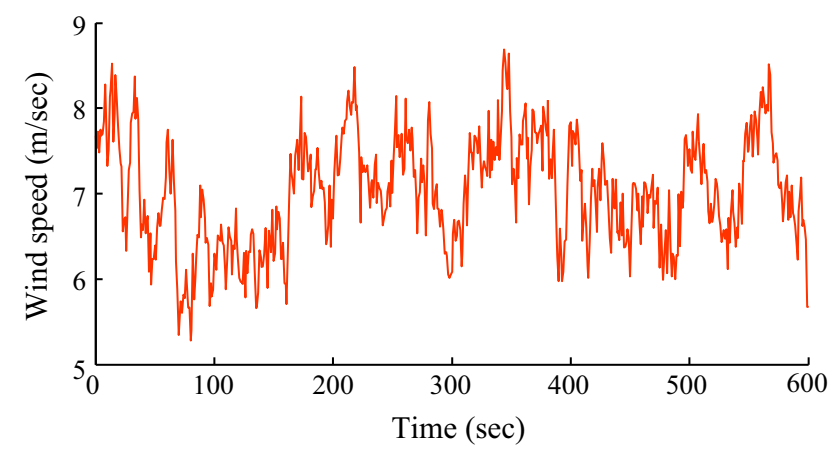

Fig. 3 Wind speed profile 


$$
\eta_{\text {elec }}(\%)=\frac{\int_{t_{\text {ini }}}^{t_{\text {fin }}} P_{e} \mathrm{~d} t}{\int_{t_{\text {ini }}}^{t_{\text {fin }}} P_{a_{\text {opt }}} \mathrm{d} t}
$$

where $P_{a_{o p t}}=0.5 \rho \pi R^{2} C_{P_{\text {opt }}}$ is the optimal aerodynamic power for the wind speed profile. The following objectives are used to measure the performance of the controllers.

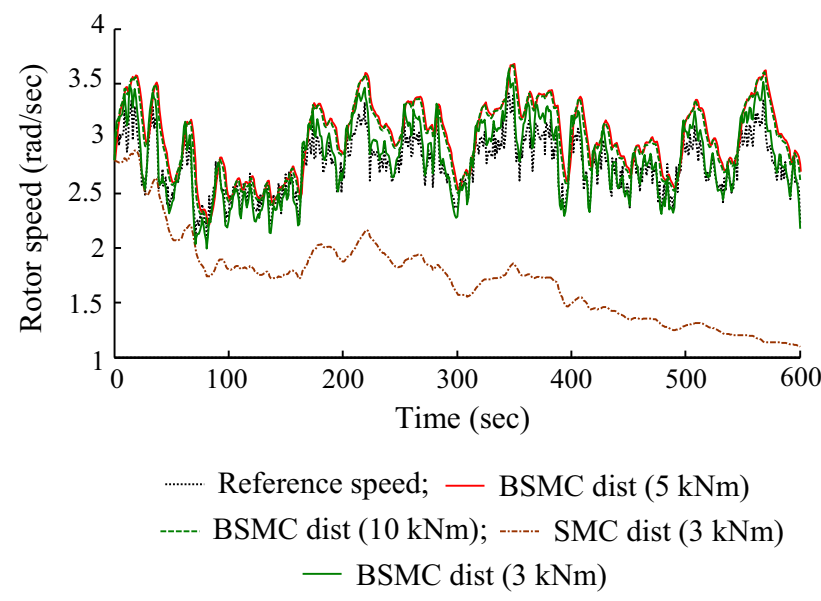

Fig. 4 Rotor speed comparison for SMC and BSMC controller for mathematical model

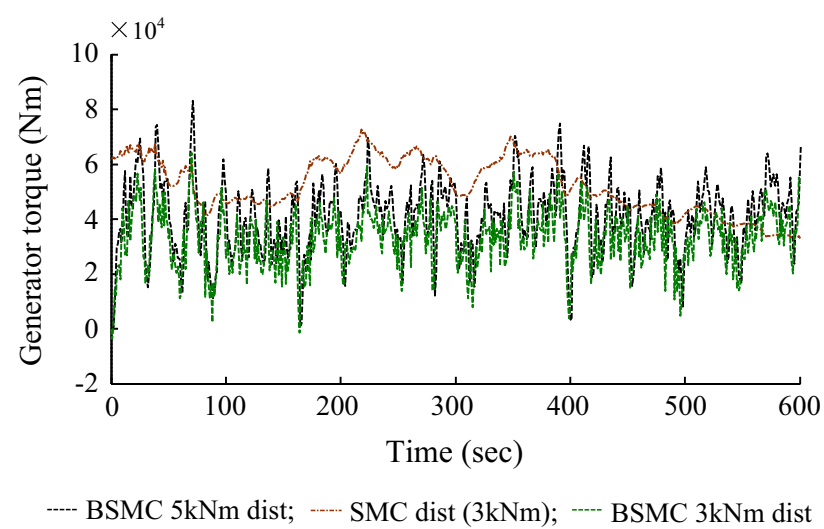

Fig. 5 Generator torque for SMC mathematical model
1) Maximization of the power capture is evaluated by the aerodynamic and electrical efficiency which is defined in the (58) and (59).

2) The reduced oscillation on the drive train and control torque smoothness are measured by the standard deviation (STD) and maximum value of $T_{g}$ at different disturbance level.

Table 2 shows the comparisons of SMC and BSMC. The main objectives of the controllers are to maximize the energy capture with reduced stress on the drive train. The efficiency of the controllers is compared by using aerodynamic efficiency $\eta_{\text {aero }}$ and electrical $\eta_{\text {elec }}$ efficiency.

From Table 2, it is clear that at $3 \mathrm{kNm}$ disturbance level SMC is not able to track the reference rotor speed due to which the efficiency drastically decreases, but BSMC can able to accommodate the disturbance level up to $10 \mathrm{kNm}$ with maximum power capture. Both electrical and aerodynamic efficiency of SMC at lower level of disturbance is almost less by $30 \%$ compared to BSMC. This shows the superior performance of BSMC over SMC. From the results, it is seen that for BSMC with an increase in disturbance level of twice i.e. from $5 \mathrm{kNm}$ to $10 \mathrm{kNm}$, the efficiency and standard deviation almost remains the same. This indicates the robustness of BSMC in the presence of disturbance. At higher level of disturbance, a tradeoff should be made between STD and maximum power capture. Finally, it is concluded that as the disturbance of WT is not predictable, it may vary on time, hence BSMC is a better controller to achieve the maximum power with acceptable variation in control input.

\subsection{FAST model with proposed and conventional controller}

Figure 6 shows the rotor speed comparison for SMC and BSMC controller for FAST WT model. Italso ensures that $\mathrm{SMC}$ is not robust with respect to disturbance level of more than $3 \mathrm{kNm}$. Figure 7 shows the generator torque for SMC and BSMC for FAST WT. This figure is further analyzed with Table 3.

Table 3 shows the comparison of control strategy for FAST WT. The results in Table 3 can be analysed in the same way as those in Table 3. As FAST dynamics is more

Table 2 Comparisons of control strategies for mathematical model

\begin{tabular}{lllll}
\hline $\begin{array}{l}\text { Control } \\
\text { schemes }\end{array}$ & $\begin{array}{l}\text { SMC } \\
(3 \mathrm{kNm} \text { disturbance })\end{array}$ & $\begin{array}{l}\text { BSMC } \\
(3 \mathrm{kNm} \text { disturbance })\end{array}$ & $\begin{array}{l}\text { BSMC } \\
(5 \mathrm{kNm} \text { disturbance })\end{array}$ & $\begin{array}{l}\text { BSMC } \\
(10 \mathrm{kNm} \text { disturbance })\end{array}$ \\
\hline $\operatorname{Std}\left(T_{g}\right)(\mathrm{kNm})$ & 11.22 & 10.55 & 13.18 & 13.23 \\
$\operatorname{Max}\left(T_{g}\right)(\mathrm{kNm})$ & 72.55 & 64.18 & 83.16 & 84.04 \\
$\eta_{\text {ele }}(\%)$ & 59.12 & 90.32 & 85.41 & 85.94 \\
$\eta_{\text {aero }}(\%)$ & 61.91 & 91.87 & 87.87 & 88.34 \\
\hline
\end{tabular}




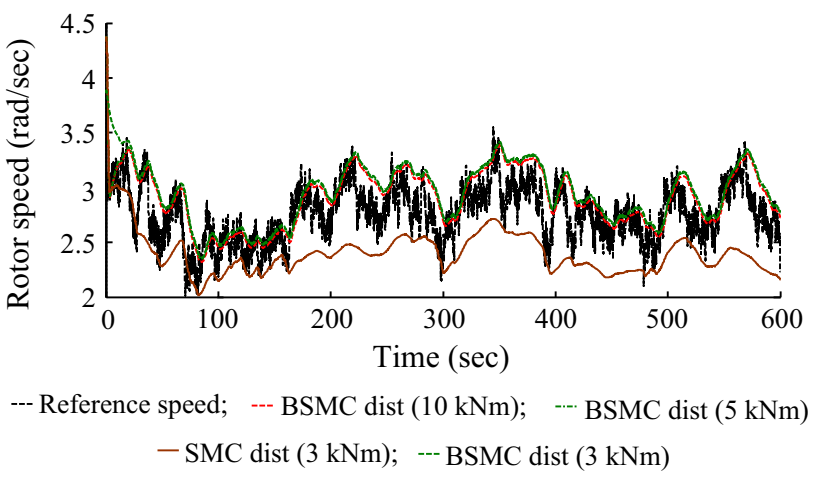

Fig. 6 Rotor speed comparison for FAST model

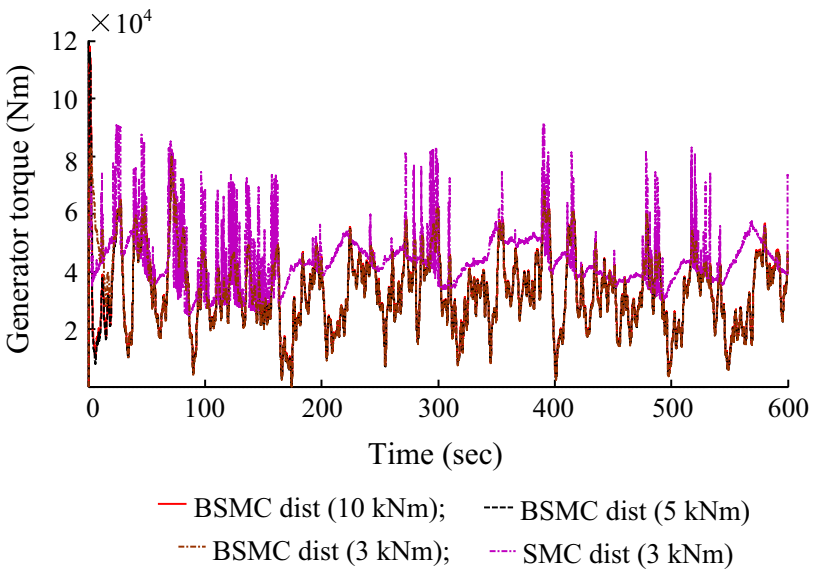

Fig. 7 Generator torque comparison for FAST model

Table 3 Comparisons of control strategies for FAST WT

\begin{tabular}{lllll}
\hline $\begin{array}{l}\text { Control } \\
\text { schemes }\end{array}$ & $\begin{array}{l}\text { SMC } \\
(3 \mathrm{kNm} \\
\text { disturbance })\end{array}$ & $\begin{array}{l}\text { BSMC } \\
(3 \mathrm{kNm} \\
\text { disturbance })\end{array}$ & $\begin{array}{l}\text { BSMC } \\
(5 \mathrm{kNm} \\
\text { disturbance })\end{array}$ & $\begin{array}{l}\text { BSMC } \\
(10 \mathrm{kNm} \\
\text { disturbance })\end{array}$ \\
\hline $\begin{array}{c}\text { Std }\left(T_{g}\right) \\
(\mathrm{kNm})\end{array}$ & 10.28 & 13.41 & 13.56 & 13.63 \\
$\begin{array}{c}\mathrm{Std}\left(T_{\text {ls }}\right) \\
(\mathrm{kNm})\end{array}$ & 23.56 & 11.98 & 11.79 & 11.85 \\
$\begin{array}{c}\eta_{\text {ele }}(\%) \\
\eta_{\text {aero }}(\%)\end{array}$ & 56.21 & 73.39 & 71.71 & 72.18 \\
\hline
\end{tabular}

Table 4 BSMC performance for different wind speed profiles

\begin{tabular}{llll}
\hline $\begin{array}{l}\text { Mean wind } \\
\text { speed }(\mathrm{m} / \mathrm{sec})\end{array}$ & $\begin{array}{l}\text { Electrical } \\
\text { efficiency }(\%)\end{array}$ & $\begin{array}{l}T_{l s} \text { standard } \\
\text { deviation }(\mathrm{kNm})\end{array}$ & $\begin{array}{l}\mathrm{std} T_{g} \\
(\mathrm{kNm})\end{array}$ \\
\hline 8 & 70.50 & 11.64 & 12.84 \\
8.5 & 70.11 & 12.93 & 12.03 \\
\hline
\end{tabular}

accurate and more degrees of freedom have been taken into consideration, it can be shown that the efficiency decreases and the STD increases as compared to simplified



Control strategy with presence of $3 \mathrm{kNm}$ disturbance

Fig. 8 Boxplot comparison for different control strategy

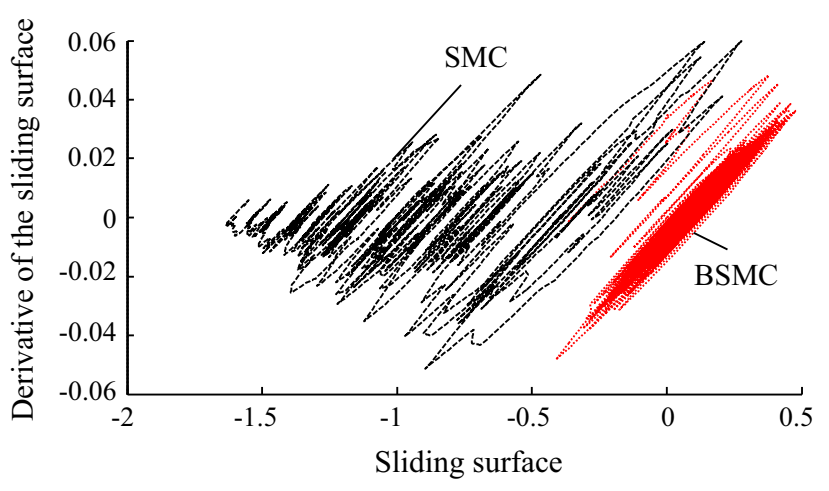

Fig. 9 Phase plot for SMC and BSMC

mathematical model. Here, it can also be seen that SMC is having poor performance compared to BSMC. BSMC is able to track the reference rotor speed in extracting maximum power from the wind with more robustness.

Table 4 shows the different mean wind speed for FAST WT model. In order to analyze the adaptability of the BSMC, the simulation is performed with different mean wind speed at below rated wind speed. It is clear that when a mean wind speed changes, the STD almost remains same and the controller can able to track the maximum power.

Figure 8 shows the boxplot for both the control strategies with same level of constant disturbance. Boxplot can able to identify the variation in the low speed shaft torque. It is clear that SMC has more variation compared to the BSMC. This figure ensures BSMC is robust with different disturbance levels.

Figure 9 shows the stability plot for SMC and BSMC. From this plot it is clear that SMC is losing the stability because the surface is not able to stay on the origin. But in BSMC case, most of the points stay near the origin. This ensures BSMC is more stable than SMC with presence of constant disturbances. 


\section{Conclusion}

In this paper, a nonlinear control of variable speed WT is proposed. The main aim is to maximize the energy capture from the wind with reduced oscillation on the drive train. Initially, the WT dynamics is considered as the single mass model, and estimation of effective wind speed is done by MNR based estimator. The proposed BSMC and conventional SMC are initially tested with different magnitude of disturbance for the mathematical model. Finally, the same controllers are validated through FAST nonlinear WT model with more degrees of freedom. From the analysis, it is found that SMC is not able to achieve the objectives for a disturbance more than $3 \mathrm{kNm}$. The proposed BSMC can able to accommodate a constant disturbance of $10 \mathrm{kNm}$ without any appreciable change in controller performance. After going through the simulation results, it can be concluded that, for better performance of the controller, a compromise should be made between the maximum power capture and reduced transient load on the drive train. Finally, different mean wind speeds are used for testing the BSMC controller with the presence of disturbances, and it ensures adaptability of the proposed controller.

Open Access This article is distributed under the terms of the Creative Commons Attribution License which permits any use, distribution, and reproduction in any medium, provided the original author(s) and the source are credited.

\section{References}

[1] Oghafy V, Nikkhajoei H (2008) Maximum power extraction for a wind-turbine generator with no wind speed sensor. In: Proceedings of the IEEE Power and Energy Society general meeting: Conversion and delivery of electrical energy in the $21 \mathrm{st}$ century, Pittsburgh, PA, USA, 20-24 Jul 2008, 6 pp

[2] Ackerman T, Söder L (2002) An overview of wind energy status 2002. Renew Sustain Energy Rev 6(1/2):67-128

[3] Petkovic D, Cojbasic Z, Nikolic V et al (2014) Adaptive neurofuzzy maximal power extraction of wind turbine with continuously variable transmission. Energy 64(1):868-874

[4] Ro K, Choi HH (2005) Application of neural network controller for maximum power extraction of a grid-connected wind turbine system. Electr Eng 88(1):45-53

[5] Seker M, Zergeroglu E, Tatlicioglu E (2013) Non-linear control of variable-speed wind turbines with permanent magnet synchronous generators: a robust backstepping approach. Int J Syst Sci. doi:10.1080/00207721.2013.834087

[6] Jovan OMR, Luis TA (2012) Maximizing the performance of variable speed wind turbine with nonlinear output feedback control. Procedia Eng 35:31-40

[7] Eltamaly AM, Farh HM (2013) Maximum power extraction from wind energy system based on fuzzy logic control. Electr Power Syst Res 97:144-150
[8] Jafarnejadsani H, Pieper J, Ehlers J (2013) Adaptive control of a variable-speed variable-pitch wind turbine using radial-basis function neural network. IEEE Trans Control Syst Technol 21(6):2264-2272

[9] Boukhezzar B, Siguerdidjane H, Maureen Hand M (2006) Nonlinear control of variable-speed wind turbines for generator torque limiting and power optimization. J Solar Energy Eng 128(4):516-530

[10] Boukhezzar B, Siguerdidjane H (2011) Nonlinear control of a variable-speed wind turbine using a two-mass model. IEEE Trans Energy Convers 26(1):149-162

[11] Saravanakumar R, Jena Debashisha (2014) Variable speed wind turbine for maximum power capture using adaptive fuzzy integral sliding mode control. J Mod Power Syst Clean Energy 2(2):114-125

[12] Saravanakumar R, Jena Debashisha (2014) Adaptive fuzzy sliding mode control for variable speed wind turbine for maximum power capture. WSEAS Trans Power Syst 9:281-290

[13] Ran L, Xiang DW, Kirtely JL (2011) Analysis of electromagnetic interactions in a flywheel system with a doubly fed induction machine. IEEE Trans Ind Appl 47(3):1498-1506

[14] Merabet A, Beguenane R, Thongam JS et al (2011) Adaptive sliding mode speed control for wind turbine systems. In: Proceedings of the on 37th annual conference on IEEE Industrial Electronics Society (IECON'11), Melbourne, Australia, 7-10 Nov 2011, pp 2461-2466

[15] Lin FJ, Shen PH, Hsu SP (2002) Adaptive backstepping sliding mode control for linear induction motor drive. IEE Proc-Electr Power Appl 149(3):184-194

[16] Chen NJ, Song FZ, Li GP et al (2013) An adaptive sliding mode backstepping control for the mobile manipulator with nonholonomic constraints. Commun Nonlinear Sci Numer Simul 18(10):2885-2899

[17] Phillip JD (2009) Wind turbine control design to reduced capital cost. Technical Report, National Renewable Energy Laboratory (NREL), Washington, DC, USA

[18] Slotine JJE, Li WP (1991) Applied nonlinear control. Prentice Hall, Englewood Chiffs

Saravanakumar RAJENDRAN received the Master degree in Electrical Engineering from Anna University, Coimbatore Region, India, 2010. Currently, he is pursuing the Ph.D. degree in the Department of Electrical \& Electronics Engineering, National Institute of Technology Karnataka, Surathkal, India.

Debashisha JENA received his Bachelor of Electrical Engineering degree from University College of Engineering, Burla, India, in 1996 and Master degree of Technology in Electrical Engineering in 2004 and $\mathrm{Ph} . \mathrm{D}$. degree in Control System Engineering from the Department of Electrical Engineering, National Institute of Technology, Rourkela, India, 2010. He was awarded a GSEP fellowship in 2008 from Canada for research in control and automation. Currently, he is an Assistant Professor in the Department of Electrical \& Electronics Engineering in the National Institute of Technology Karnataka, Surathkal, Mangalore, India. His research interests include evolutionary computation, system identification and neuro-evolutionary computation. 